\title{
Editorials
}

\section{Alcohol and health: what is good for the French may not be for the Russians}

The countries of central and eastern Europe are characterised by some of the world's highest premature death rates in middle aged men. ${ }^{12} \mathrm{~A}$ considerable part of the epidemic of man made diseases observed in recent decades in this region is accounted for by diseases caused by alcohol..$^{3-5}$ In general, an increase in alcohol consumption was observed in central and eastern European countries after the second world war, and negative health effects (including liver cirrhosis, deaths from external causes, etc) accompanied this. ${ }^{2-5}$

After 1980, changes in the economic and political situation in several countries, at different times, lead to striking fluctuations in alcohol consumption. ${ }^{4}$ As a result, a series of extraordinary natural experiments in the health effects of alcohol were conducted among the populations of eastern Europe.

In chronological order, the most dramatic fluctuations in alcohol consumption occurred in 1980-82, in Poland, when martial law was established and the availability of alcohol was regulated-that is, vodka was rationed. ${ }^{6}$ In 1984-86, in the former USSR, Gorbachev implemented a wide ranging and effective anti-alcohol campaign. ${ }^{4}$ In 1988-91, in Poland, import duty on alcohol was abolished and millions of litres of very cheap alcohol were imported and distributed in what became known as the "Schnapsgate" affair. ${ }^{6}$ Finally, after 1991, following the break up of the former USSR, apart from widespread smuggling operations, there was a sudden increase in alcohol production, both legal and illegal, through private initiatives, resulting in an abundance of alcoholic beverages sold at very low prices everywhere (for example in plastic cups in kiosks). ${ }^{4}$

These unprecedented population wide natural experiments and their health effects are all the more interesting because of the distinctive alcohol drinking styles observed in central and eastern Europen countries, as well as the different types of alcohol commonly consumed. In the Czech and Slovak Republics, beer is most popular, in Hungary and Slovenia a substantial share of total consumption consists of concentrated dark fruit alcohol, often made at home. In Poland and countries of the former USSR a concentrated alcohol produced from potatoes and grain (vodka) is commonly consumed.

Another characteristic of the drinking style in Poland and countries of the former USSR is the high incidence of binge drinking, when large amounts of alcohol are consumed in short periods of time, often leading to deep intoxication.

The level of alcohol consumption, the style of alcohol consumption (in many countries traditionally binge drinking), huge fluctuations in alcohol consumption have all lead to dramatic consequences for health in central and eastern European countries.

In Hungary, there has been an extraordinary increase in the incidence of and mortality from liver cirrhosis (a disease closely related to alcohol consumption) to a rate never before recorded anywhere in the world, in both men and women but mainly among young and middle aged adults. $^{8}$ Mortality from liver cirrhosis in the 20-44 age group reached a level of 70 deaths per 100000 for men and 25 deaths per 100000 for women; a level almost seven times higher for men and three times higher for women than the highest level ever recorded in France. ${ }^{9}$

Yet from the epidemiological viewpoint, the mortality trends seen in central and eastern European countries where there were extreme fluctuations in alcohol consumption are even more interesting than the developments in Hungary.

In Poland, as in the countries of the former USSR, the rise and fall in alcohol consumption lead to predictable and expected effects such as: increases and corresponding decreases in deaths from liver cirrhosis, sudden death from external causes, etc, synchronised in time with exposure to alcohol. Unexpectedly, however, at the same time there were sharp increases and decreases in cardiovascular mortality. ${ }^{23} 5$ These changes can be seen most clearly in Russia (although they occurred in Poland and other countries of the former USSR as well, at different times). Gorbachev's anti-alcohol policy in the mid-1980s led to a significant drop in cardiovascular mortality, while the increase in alcohol consumption after the USSR's breakup caused a corresponding dramatic jump. The level of cardiovascular disease mortality in 1994 in Russian men in middle age (45-64) reached 1356 per 100000 (from 822 in 1991) and in women of the same age group 486 per 100000 (from 317 in 1991) - a level unprecedented in the history of recorded mortality in the world. ${ }^{5910}$

The key to understanding cardiovascular disease mortality trends could be the findings of a prospective cohort of a few thousand alcohol drinking men in Finland published in 1997. This study demonstrated that, after standardisation of the amount of alcohol consumed, drinking style had a very significant influence on increased risk of lethal myocardial infarction. The risk of lethal myocardial infarction was seven times higher for those who drank six or more bottles of beer at one sitting (binge drinkers) compared with those who drank three bottles or less. ${ }^{11}$ The dominant style of drinking in Russia, as well as other countries of the former USSR and Poland, is precisely that of consuming large amounts of alcohol at one sitting.

Further evidence supporting this hypothesis is the work by Chenet et al in this issue. ${ }^{12}$ The heightened levels of cardiovascular disease mortality on Saturdays, Sundays, and Mondays correspond to the timing and style of drinking in Russia and other central and eastern European countries.

Although full understanding of this phenomenon requires further research, the sharp decreases and rises in cardiovascular mortality and their close correlation with alcohol consumption encourage a reassessment of our ideas about the health effects of alcohol, most of all regarding sudden cardiac deaths.

WITOLD ZATONSKI

Department of Cancer Epidemiology and Prevention,

The M Sktodowska-Curie Memorial Cancer Centre and Institute of

Oncology, 5 wk Roentgena str, 02-781 Warsaw, Poland

1 Murray C, Lopez A. Global and regional cause-of-death patterns in 1990. Bull World Health Organ 1994;72/3:447-80. 
2 Zatoński W. The health of the Polish population. Public Health Rev 1995;23: 139-56.

3 Zatoński WA, Boyle P. Commentary: Health transformations in Poland after 1988. Fournal of Epidemiology and Biostatistics 1996;1:183-97.

4 Simpura J Alcohol and European transformation. Addiction 1997:92:33-41. 5 Lehto J. Alcohol and the future health of Europe. Addiction 1997b;92:91-6. 6 Światkiewicz G. Regulating unregulated markets. Addiction 1997;92:67-71. 7 Lehto J. The economic of alcohol. Addiction 1997a;92:55-9.

8 Varvasovsky Z, Bain C, McKee M. Deaths from cirrhosis in Poland and Hungary: the impact of different alcohol policies during the 1980s. F Epidemiol Community Health 1997;51:167-71.
9. World Health Organization. Mortality statistics. WHO, 1997.

10 Zatoński WA, McMichael AJ, Powles JW. Ecological study of reasons for sharp decline in mortality from ischaemic heart disease in Poland since 1991. BMf 1998:316:1047-51.

11 Kauhanen J, Kaplan GA, Goldberg DE, et al. Beer drinking and mortality: results from the Kuopio ischaemic heart disease risk factor study, a prospective population based study. BMf 1997:315:846-51.

12 Chenet L, McKee M, Leon D, et al. Alcohol and cardiovascular mortality in Moscow; new evidence of a causal association. F Epidemiol Community Health1998;52:772-4.

\section{$\mathrm{JECH}$ and the world wide web}

Visitors to the world wide web can now access the fournal of Epidemiology and Community Health either through the BMJ Publishing Group's home page (http://www.bmjpg.com) or directly by using its individual URL (http://www.jech.com). There they will find the following:

- Current contents list for the journal

- Contents lists of previous issues

- Members of the editorial board

- Subscribers' information

- Instructions for authors

- Details of reprint services.

Hotlink

A hot link gives access to:

- BMJ Publishing Group home page

- British Medical Association website

- Online books catalogue

- BMJ Publishing Group books.

\section{Suggestions welcome}

The website is at a preliminary stage and there are plans to develop it into a more sophisticated site. Suggestions from visitors about features they would like to see are welcomed. They can be left via the opening page of the BMJ Publishing Group site or, alternatively, via the journal page, through "about this site". 